\title{
ENSINO COMO ENSAIO PARA ABRIR OS CORPOS: uma didática do acesso pela pele
}

\author{
Lindsay Gianuca \\ Silvia Balestreri
}

\section{Resumo}

Este artigo aproxima ensino e ensaio como práticas laborais de aprimoramento técnico e exercício do pensamento. Fomentado por estudos prévios acerca destas nuances comparativo-operativas e pela experiência docente de uma das autoras que, de performer se viu professora, exibe alcances possíveis dos acoplamentos filosofia-docência, treinamento-criação-ensino. Movimentos conceituais conduzem a observação que considera a pele como superfície de acesso e uma antropologia como inspiração. Aliado às filosofias de Deleuze e Guattari, pensa a aprendizagem como exercício de deslocamento e os corpos em seus aspectos relacionais. Nesta perspectiva, revela a invenção de procedimentos e a emancipação dos corpos através do conceito de forças. Considerando que cada corpo é um aprendiz e defendendo que ensinar é a ação de abrir, aumento de potências, pensa a didática como projeto coletivo de ensinoaprendizagem.

Palavras-chave: pele; corpo; forças; ensino

\section{TEACHING AS A REHEARSAL TO OPEN THE BODIES: didactics of access through the skin}

\begin{abstract}
This paper approaches teaching and rehearsal as labour practices for improving techniques and for exercising thought. Fed by previous studies on these comparative-operative nuances and by one of the author's experience who from performer caught herself as a teacher, it exposes some reaches of the coupling philosophy-teaching and training-creating-learning. Conceptual movements lead the perspective that considers the skin as an access surface and one anthropology as an inspiration. Allied to Deleuze and Guattari's concepts, it takes learning as a displacing exercise and the bodies in their relational aspects. From this perspective, it also thinks about the invention of procedures and the bodies' emancipation through the concept of forces. Considering that each body is a learner in itself and defending that to teach is to open, power increase, reflects on the didactics as a collective project of teaching-learning.
\end{abstract}

Keywords: skin; body; forces; teaching

\section{LA ENSEÑANZA COMO ENSAYO PARA ABRIR LOS CUERPOS: una didáctica del acceso por la piel}

Resumen

Este artículo aborda la enseñanza y el ensayo como prácticas laborales para la mejora técnica y el ejercicio del pensamiento. Animada por los estudios de estos matices comparativo-operativos y por la experiencia docente de una de las autoras que, desde performer se cambió en profesora, aproxima filosofía-enseñanza, formación-creación-aprendizaje. La narrativa considera la piel como superficie de acceso y una antropología como inspiración. Aliada a los conceptos de Deleuze y Guattari, piensa el aprendizaje y los cuerpos por sus aspectos relacionales, reflexiona sobre la invención de procedimientos y la emancipación de los cuerpos por el concepto de fuerzas. Considera el cuerpo como un aprendiz y defiende que la enseñanza es la acción de abrir, potencias aumentadas, piensa la didáctica como proyecto colectivo de enseñanzaaprendiraje.

Palabras clave: piel; cuerpo; fuerzas; enseñanza. 


\section{ACESSAR}

Ensinar e ensaiar se aproximam como verbos de processos, e suas possíveis relações são o estopim para as reflexões expostas nestas páginas. Extrato de pesquisa doutoral ${ }^{1}$, este estudo contempla três movimentos didáticos experimentados através de uma experiência docente junto a um curso de Teatro-Licenciatura ${ }^{2}$. Tais observações partem de um corpo performático, ensaiado como atriz e bailarina, treinado para os palcos, interessado na relação com o público, que assumiu o ensino como prática tardia, mas não por isso menos potente, e que esteve também por quase toda a vida se aprimorando como estudante. Foi-se muito aluna para professorar, performer para filosofar, um pouco antropóloga para compor estas linhas.

$\mathrm{Na}$ sala de aula, este lugar anterior ao palco, anterior às coxias, anterior às salas de ensaio, no qual quase todo corpo já esteve, e cuja trama ensino-aprendizagem se manifesta tão múltipla e potente quanto perigosamente restritiva e engessante, a relevância de um trabalho sobre a pele ganhou protagonismo. Talvez pelas experiências prévias em salas de ensaio, desta vez a sala de aula se revelou cenário singular para as observações acerca dos treinamentos, das técnicas, da produção de pensamento e das práticas de ensino. Apropriamos a função didática relacionando-a à função antropológica de pisar em territórios alheios e se abismar diante da estranheza que o encontro com o outro evidencia. O corpo performer-ensaio-palco se transformou em aulaprofessora-pedagoga e por necessidade cavou uma didática possível pela pele que o compunha.

Dada a natureza de um curso de licenciatura em teatro, a incumbência de formar futuros professores somava-se à necessidade de construção de corpos criadores, ao estudo e formulação sobre estados expressivos e, inevitável ao corpo que lecionava, também à incursão filosófica que embasava os encontros. Por sentir que chegava tardiamente ao ofício de professora, assumiu-se como professora-aprendiz e, com O Mestre Ignorante (RANCIÈRE, 2004) embaixo do braço, pôsse o corpo no risco de ensinar. O primeiro movimento então foi abrir os próprios poros, expor a pele para a atividade docente. A prática do ensino se apossou do corpo da professora-aprendiz e, ao fazê-lo, possibilitou-lhe descobrir operações que se aproximam dos ensaios que antecedem uma estreia, ou dos passos de um antropólogo que encontra um povo. O corpo da performer acoplou a função de professora, impregnando-se da docência. Um novo corpo, até então desconhecido, tomava vida, e algumas das descobertas que fez permitiram aproximar o ensino às práticas de ensaio para a cena, como pensamos um ator para uma personagem ou um bailarino para um movimento: processos de acesso, práticas de ampliação de possíveis - abrindo os corpos.

Alguns conceitos especialmente desenvolvidos nas chamadas filosofias da diferença motivavam os encontros, as práticas e as discussões. Um dos principais expoentes para introdução de um modo de pensamento é o conceito de forças que contribuiu para enfraquecer as noções de certo e errado, autorizando a experimentação e expansão dos corpos em suas ações no mundo. Vale dizer que a professora-aprendiz se desdobrava ao conduzir matérias eminentemente práticas e outras de cunho predominantemente teórico da grade curricular. Independentemente do caráter das aulas, começava por apresentar o princípio que regeria os encontros: a observação das operações de forças. O pensamento que assim se antecipava, reconhecendo as intensidades das forças, colocava de antemão a relativização dos próprios espaços de poder, da hierarquia de conhecimento, convidando a uma investigação sobre os procedimentos e potências de cada

\footnotetext{
${ }^{1}$ Pesquisa contemplada com financiamento CAPES através do Programa Institucional de Internacionalização no ano de 2019.

2 As informações completas serão acrescidas após a avaliação deste artigo a fim de evitar identificação de autoria.
} 
corpo. Importante assinalar que o termo corpo aqui corresponde a um corpopensamento cuja matéria ${ }^{3}$ é nossa experiência singular de estar e atuar no mundo, de criar novos mundos e inventar modos próprios, pedagogias possíveis.

Assim como um antropólogo que observa um povo e contrasta cultura e hábitos, no exercício da exaltação da diferença em oposição ao de dominação do colonizador, a professoraaprendiz se via diante da pluralidade dos corpos, contrastando temporalidades, habilidades, saberes, interesses, modos, etc. Nas suas leituras de Michel Foucault (2001; 2004), por exemplo, observava como a formação dos corpos em vias de promover suas amplas capacidades se daria antes numa de-formação das formas e hábitos apreendidos. Juntamente às abordagens sociológica e filosófica sobre o disciplinamento dos corpos, nos campos da dança e do teatro, encontrava princípios similares em distintos autores que, como artistas, se dedicaram a pensar o movimento humano ou a atuação ${ }^{4}$. Então, o exercício se faria por abrir os corpos: como cavar as amplitudes criativas, como fazer aqueles futuros professores conquistarem modos próprios de ensinoaprendizagem? Como ampliar a matéria corpopensamento para seguir ampliando por decorrência do que experimenta? Experimentando o pensamento?

A expressão "experiência de pensamento" não tem o sentido usual de entrada imaginária na experiência pelo pensamento, mas o de entrada no pensamento pela experiência real. Não se trata de imaginar uma experiência, mas de experimentar uma imaginação, ou de "experimentar o pensamento ele próprio." (VIVEIROS DE CASTRO, 2015, p. 217)

O antropólogo Eduardo Viveiros de Castro defende ser a antropologia uma ciência menor por basear-se no exercício de descolonização do pensamento. No teatro e na literatura, através de Deleuze e Guattari, observamos como forças desestabilizadoras de instâncias de poder se riscam nas encenações de Carmelo Bene (DELEUZE, 2010, p. 60; BALESTRERI, 2004; 2005) ou como Kafka traça uma língua menor dentro da língua maior (DELEUZE, GUATTARI, 2014), pondo em operação forças específicas que fazem emergir um Teatro Menor e uma Literatura Menor, respectivamente. Pois bem, tais termos têm em comum a operação de traçar movimentos inaugurais, sempre políticos e coletivos, não se referindo às minorias, mas à desestabilização do fato majoritário. Ora, e o que isso quer dizer quando apropriamos tais análises para o que fazemos em sala de aula? Uma reunião coletiva que compreende professor e estudantes é uma partícula operativa no seio majoritário das instituições, dos pilares do conhecimento, da estratificação dos métodos, dos rigores curriculares, uma sala de aula é um

\footnotetext{
3 A matéria, nas perspectivas da diferença, é atravessada pelas forças extensas em composição com as forças das intensidades. Num plano de composição artística, por exemplo, é preciso extrair a matéria de expressão do material. "O objetivo da arte, com os meios do material, é arrancar os perceptos das percepções, do objeto e dos estados de um sujeito percipiente, arrancar os afectos das afecções, como passagem de um estado a outro." (DELEUZE, GUATTARI, 1992, p. 217). O corpo, nesta perspectiva, é matéria e material das práticas de movimento e pedagógicas que o estudo observa. "Toda matéria se torna expressiva”, quando as forças das sensações se compõem com o material.

4 Para citar apenas alguns: na pesquisa sobre o movimento humano, Rudolf Laban (1879-1958), dançarino, coreógrafo, intérprete, considerado “[...] pai da análise do movimento e da dança-teatro"; Pina Bausch (1940-2009), bailarina e coreógrafa alemã, pedagoga do movimento; Martha Graham (1894-1991), bailarina e corógrafa norteamericana que revolucionou a dança moderna. No teatro, por exemplo, Constantin Stanislavski (1863-1938) ator, diretor, pedagogo e encenador russo, famoso mundialmente por seu sistema de treinamento do ator; Jerzy Grotowski (1933-1999) diretor polonês, teorizou um "teatro pobre" baseado no trabalho psicofísico do ator, interessado na organicidade da atuação; Eugenio Barba (1936) ator, diretor e pesquisador teatral, fundador e diretor do Odin Teatret, criador do ISTA (International School of Theatre Anthropology), considerado o pai da antropologia teatral.
} 
campo de forças repleto de potências ${ }^{5}$ inventivas pelo contágio de corpos em expansão de suas matérias. "A alegria de um professor é incorporar sua matéria, fazer de si próprio prova do pensamento que a matéria põe a funcionar" (ZORDAN, 2019, p. 27).

Considerando as salas de aula território privilegiado para pôr o pensamento em movimento - predileção de uma filósofa que dança, ou de uma bailarina que cria conceitos —, o ensino se aproxima de uma prática de ensaio em que as técnicas, os aspectos criativos e os empenhos críticos são evidenciados como pilares da própria didática, a qual se ergue ao mesmo tempo em que nasce (se cria). E, talvez o mais importante: o processo é explícito, exposto. Privilégio dos processos em lugar dos resultados fazendo aparecer uma didática que se interessava primeiro por um aumento de potências e que submeteria a quantificação do conhecimento e qualificação das experiências a necessários ajustes constantes de perspectiva. $\mathrm{O}$ professor, incluindo-se como parte do jogo, sem hierarquia de saberes, mas como condutor da matéria que em si mesmo testa. Para principiar tais noções e aproximações, pôr em evidência as forças ${ }^{6}$ como já anunciamos. Uma didática que começa por abrir — primeiro movimento prevê como consequência o ato de descobrir. E, como todo descobrimento, ser capaz de abismar-se: segundo movimento.

\section{PRIMEIRO MOVIMENTO - ABRIR: DIDÁTICA DO ACESSO}

Como antecipamos, a pesquisa mais ampla da qual recortamos estes apontamentos aportou na relevância de notarmos a própria pele: camada de contato com o mundo, é nela que se revela uma certa potência de acesso aos corpos (GIANUCA, 2020; 2018). "O mais profundo é a pele" diz a célebre frase de Paul Valéry apropriada por Deleuze, e o professor Máximo Adó (2014, p. 10) observa que "[...] Valéry, lido assim para servir como ferramenta para a Educação, não é um modelo, mas um modo de constituir forças fabricadoras de composições." Assim, abrir os corpos relaciona-se com abrir os poros, mas também o olhar, trabalhar as percepções. $\mathrm{O}$ encenador italiano Romeo Castelucci (2014, p. 35) esclarece que "[...] é o olhar do corpo, extremamente físico: funciona como um poro da pele por onde passam os humores, as emoções, as sensações e também o conhecimento". A pele, superfície porosa em si mesma, suscita que a matéria lhe atravesse, assim chegaremos à experimentação do pensamento ele próprio. Os

\footnotetext{
5 As forças mobilizam a potência dos devires, dos novos modos de operar no mundo, aliás da criação de novos mundos: a potência é produtora (e não reprodutora). A potência de uma vida, por exemplo, está nas forças de germinação.

${ }^{6}$ O conceito de força é considerado a partir dos estudos de Deleuze acerca da obra de Francis Bacon (2007) ou, ao lado de Guattari, quando pensam como se criam os planos das ciências, das artes ou das filosofias (1992); ou as forças de Corpos Sem Órgãos que se agitam contra os organismos (2012, p. 11-33). São potências moleculares que atravessam e desestabilizam a molaridade das estruturas de poder - aqui especialmente considerados os elementos de poder que atravessam expressões cênicas e as forças de uma violência condicional para a aprendizagem, capazes de deslocar o sujeito de um assujeitamento, habilitando-o às invenções. “O poder não está no palácio tal, na realeza tal, na instituição tal, no aparelho de estado tal: ele é sempre exercido e atravessa todos os corpos. E de que modo ele é exercido? Pela nossa sensibilidade e pela nossa linguagem.” (FUGANTI, 2007, p. 72) As forças são condição das sensações num plano de composição que trabalha com a criação de expressões e linguagens. Interessam a este estudo as forças de variação que escapam aos domínios do reconhecimento, da representação ou interpretação. Neste sentido, forças que alteram as formas e composições que solicitam o esforço para suas decifrações. Traços de individuação em lugar dos traços identitários marcam qualidades autorais e procedimentos operativos, liberando as forças de transform-ação aprisionadas pelos aparelhos de captura das estruturas edificantes. Achar os modos de fazer passar novas forças que deslocam os corpos de seus assujeitamentos técnico-expressivos é a ambição de trabalho do pensamento aqui exposto.
} 
primeiros apontamentos que se mostraram produtores de corpos interessados e engajados e permitiram relativizar instâncias limitadoras de nossa própria relação em sala de aula foi a exposição dos vetores de forças.

Figura 1: Material didático da professora-aprendiz, 2014

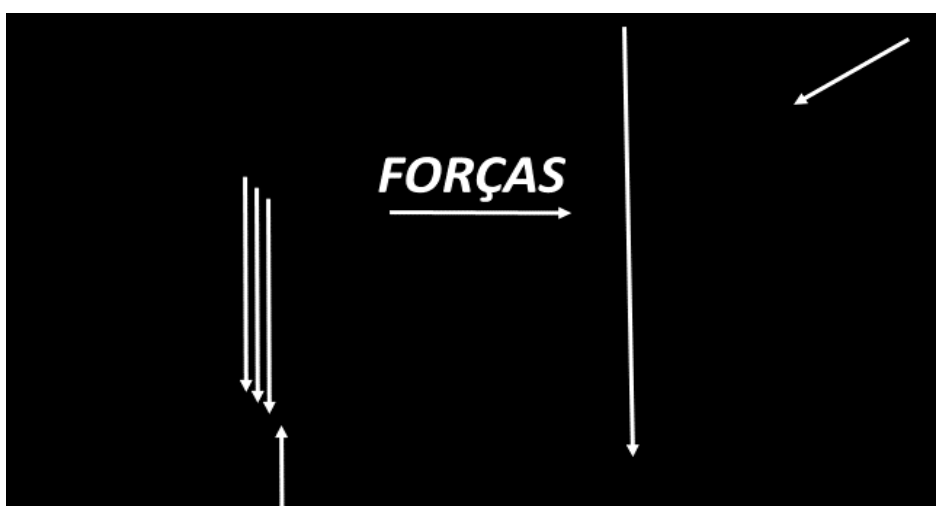

Fonte: A autora

Ao apresentar os vetores de forças e o conceito a partir da acepção filosófica que atravessa este estudo, especialmente na obra deleuziana que contempla as pinturas de Francis Bacon, colocamos em questão as Formas. "Os problemas de Bacon são problemas de deformação e não de transformação. [...] A transformação da forma pode ser abstrata ou dinâmica, mas a deformação é sempre do corpo" (DELEUZE, 2007, p. 64). O filósofo defende uma lógica da sensação que estaria inextricavelmente atrelada ao trabalho das forças. As formas, por sua vez, remetem à ideia de formação e deformação dos corpos, estruturas e posturas. Uma segunda provocação decorrente da primeira tomava lugar:

Figura 2: Material didático original, 2014. Reeditado em 2019

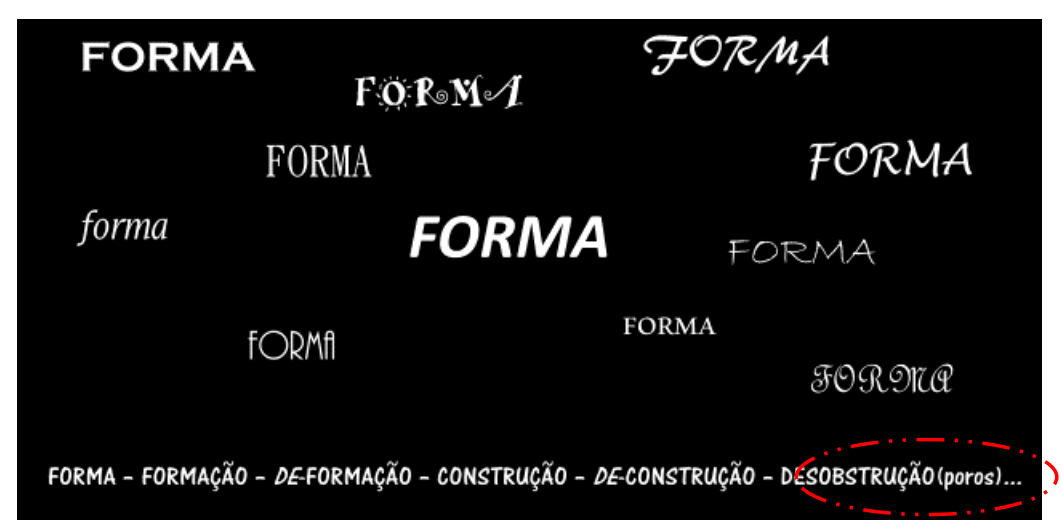

Fonte: A autora

Tornar acessível, este abrir, é procurar os acessos. Como acessar as camadas sensíveis, inteligíveis, criadoras, enraizadas, cognitivas etc. de cada corpo? Fazê-los atentar para o trabalho das forças em suas matérias-corpo se revelou produtor ${ }^{7}$ de anseios na busca por procedimentos pessoais de ensino e expressão.

\footnotetext{
7 Propositalmente usamos o termo produtor e não produtivo para marcar as distâncias entre produção de forças criadoras e padronização de forças previamente delineadas e reproduzidas.
} 
Algumas provocações conduzem o tratamento dado à matéria que se treina como estímulo ao pensamento em sua ação de mover - deslocar (GIANUCA, 2016a; 2016b). Um trabalho do corpo em seu status relacional - pela própria pele. "Que forças atravessam o corpo promovendo-lhe o arrepio?", indagava a professora-aprendiz. Forças capazes de levantar os pelos, involuntariamente, da pele. "Que forças nos fazem fechar os olhos? Que forças compõem os medos? E quais nos retiram de lá?" As forças da fome, instinto(s) de sobrevivência. "Que forças produzem voz no corpo? Quais fazem convergir às nossas figuras cênicas a atenção das testemunhas/público, ou ao corpo e voz do professor a atenção das testemunhas/estudantes?" Éramos todos aprendizes. Práticas de movimento, é a isto que temos nos dedicado: professoras de perguntas.

A professora-aprendiz e seus estudantes se encontravam uma vez por semana, ao longo de um semestre. Pouco, muito pouco, pouquíssimo para um exercício mais aprofundado das qualidades performáticas nos corpos, para o aprimoramento de suas práticas didáticas ou para a incitação (a)efetiva de um pensamento poroso (conceito derivado deste estudo). Assim, provocálos à experimentação e à observação das forças em seus corpos, vozes, movimentos, técnicas, didáticas era também um jeito de estender as aulas. Pedir que se observassem cotidianamente e extra-cotidianamente com as proposições da antropologia teatral (BARBA, SAVARESE, 1995) e o estímulo dos vetores de forças que marcam tais distâncias. Especialmente, aceitarmos que as forças são móveis e assim como a professora-aprendiz "deu" umas aulas "mais fracas" que outras, eles também apresentavam seus episódios de fortalecimento e enfraquecimento dos corpos em estado de performance, promoção de movimentos, em suas experiências de docência e experimentações do pensamento, treinando-se(nos) como poder de passagem para uma qualidade de ensino que se ensaiava. Pensar porosamente seria mover-se pelos estratos, excitar a(s) atenção(ões), fazer a carne atravessar-se de forças. Horas preenchendo, horas esvaziando a matéria, treinar o(s) fluxo(s): “[...] um pré-requisito do esvaziamento é ser capaz de perceber do que se está repleto” (SONTAG, 1987, p. 30).

Ora, em consonância com as proposições filosóficas deste estudo e que irrigaram as aulas sobre as quais nos debruçamos, a violência é a própria condição da aprendizagem: "[...] que violência se deve exercer sobre o pensamento para que nos tornemos capazes de pensar?", (DELEUZE, GUATTARI, 1992, p. 73). Atentar para os exercícios das forças que oprimem, expandem, desviam, erguem, estruturam, desconstroem, deformam, capturam, liberam etc. parece ser uma das primeiras atividades para constituição de tal prática-pensamento. Observando as forças somos capazes de reconhecer nossas próprias armadilhas, a percepção é uma propriedade dos corpos que exige ser ensaiada. "Atenção: percepção requer envolvimento" diz a frase da obra de Antoni Muntadas (2002), cartaz apropriado para as aulas que era exibido quando a dispersão tomava conta dos corpos e a potência vocal da matéria-condutora-professora via suas forças em esgotamento. $\mathrm{O}$ termo envolvimento remete à pele de volta. Recorremos às obras, às palavras, aos estudos e investigações traçados por outros artistas e autores como recurso didático, resgate de forças, porque nos compomos das alianças cujas forças nos atravessam, afinal. Se o reconhecimento, a representação e a interpretação são falsas ideias de pensamento, é necessário, à luz do que observa Susan Sontag, sermos capazes de perceber do que estamos repletos. O esvaziamento é o exercício possível para autorizar processos mais autônomos de criação e disseminação do conhecimento, não para chegar a um lugar que corresponderia ao vazio, mas para treinar a eliminação do que nos enfraquece e permitir que apareçam formas próprias, procedimentos "seus", didáticas muito pessoais que potencializam os corpos para um ensino autoral e que teriam a função de continuar abrindo. 
Ensaiando o exercício para o exercício das diferenças ${ }^{8}$. O que chamamos de presença cênica, não são afinal forças? E quais as forças, na elaboração de uma aula, a tornam mais ou menos potente? Abrir: metodologicamente, passamos por este verbo-movimento. Não como metáfora, mas como desobstrução dos poros da pele a partir da percepção das forças que nos atravessam. Abrir como movimento de ampliação das potências, entendendo as forças como conceito operativo sobre as formas e matérias, parece ser o primeiro deslocamento para uma didática de acesso aos corpos - produção de pensamento pela experiência. Poroso: ensaio de possibilidades.

\section{SEGUNDO MOVIMENTO - DESCOBRIR: O ESTRANHO SOU EU!}

Em decorrência do primeiro movimento, quando rompemos a rigidez dos corpos e os notamos engajados na perscrutação de suas "propriedades" e apropriações, a dança desta didática ensaiada se estende ao que se descortina. Lembrando que se trata sempre de expor o próprio corpo: a velha máxima de "ensinar pelo exemplo". E, como premissa do que está implicado nos ensaios, é previsto que a matéria corpopensamento se enfraqueça, se esgote, reconheça-se insuficiente em dados momentos. É numa brecha do enfraquecimento que se exige que cavemos o próprio pensamento, exercício de criação de novas forças, e que nos abismamos diante de nossos processos e constituições, e aí habilitamo-nos às invenções. Pensamos o termo in-vento com a provocação de fazer ventar: como força da natureza que desloca. Abrir uma porta que provoca uma corrente de ar. Trazer mais ar para dentro: promover passagem. Um(a) professor(a) um pouco descabelado(a), talvez, mas cuja matéria evidenciada prova o fato e o efeito de se pôr na prática de ensino: aprendendo.

Quando se está "[...] praticando com Deleuze" somos conduzidos a uma "[...] nova concepção de aprendizagem", guiada pelos encontros: “[...] o conceito de aprendizagem geralmente significa: passagem da ignorância ao conhecimento. [...] Aprender não é sobre obtenção de informações, peças de conhecimentos, mas sobre mudar a pessoa e a coisa que você é" (ATTIWILL et al, 2017, p. 159, tradução nossa). Então, aliar-se a tais perspectivas antecipa um apreço não somente pela exaltação de alteridade - eu e outro -, mas por uma diferença em si mesma. O contraste entre um antropólogo e um povo que ele observa altera sua perspectiva sobre si: o Anti-Narciso é o livro imaginário de Viveiros de Castro (2015), um manifesto que nos convida a pensar outramente.

Quando se aliou aos estudos de Rancière sobre a emancipação intelectual, a professoraaprendiz pretendia enaltecer que o Mestre Ignorante prova sua teoria mais na atitude do mestre do que em sua ignorância. Isto posto, entender que a maestria do ofício de ensinar não está em um conhecimento prévio, adquirido e acumulado que se pretende transmitir, mas a uma ação de exposição que possibilita o trânsito no próprio encontro e que de-forma a concepção que se tem de si próprio, do mundo, e dos efeitos do ensino. O ensino, assim, não seria uma abstração constituinte de transmissão de saberes, regrada metodologicamente, estrutura rígida a ser empreendida. Ao contrário, entendemos como uma estrutura móvel, sempre por ser

\footnotetext{
8 Aqui o termo é utilizado com a apropriação das assim chamadas filosofias da diferença, para a qual a diferença é em si mesma. Distante da apreensão no sentido de diversidade, ou das diferenças culturais ou identitárias. Trata-se aqui de uma diferença variante, intensiva e inventiva. Portanto, não é a diferença que se produz em relação a um padrão, mas uma diferença capaz de lançar-nos ao impensado.

9 The concept of learning normally means: passing from ignorance to knowledge. Deleure: no. Learning is not about the attainment of information, pieces of knowledge, but about changing the person and the thing that you are. (ATTIWILL et al, 2017, p. 159)
} 
criada/descoberta, cujas didáticas se ensaiariam pela observação das forças operantes na reunião de cada coletivo. O ensino como sina do professor, sua destinação: procedimentos por serem inventados para uma didática que perseguiria o constante movimento. Precisaríamos descobrir o "anti-narciso" que catapulta experiências de pensamento. Uma didática que persegue a potência do coletivo, a fragilidade da estrutura, e que por isso é capaz de criar novas formas, colocar o movimento na ideia de formação - desta vez não o movimento de erguer, mas o de descobrir-. Estranhamento do eu. Assim, deslocar as questões "quem eu sou?", "que processos didáticos me identificam?" para as questões "como opero?", "que é isso que desconhecemos?", "que processos didáticos, neste coletivo, se criam?”.

Autorizando-nos a uma sutil adequação do termo didático, segundo sua definição no dicionário, passaríamos da "[...] arte de transmitir conhecimento" (HOUAISS, 2009) para a arte de transmutar conhecimento. E o professor só tem uma maneira de alcançar tal transmutação: implicando-se, colocando-se como matéria mesma do que ensina. Ou seja, ensinando pelo que faz passar em si mesmo, estranhando-se, confrontando-se com a necessidade de invenção de didáticas. Apesar da aparência conceitual deste estudo, tais constatações são eminentemente práticas, não se restringem aos termos revistos, definições alargadas, o ensejo filosófico da docência é uma atividade no corpo, em sua "maestria", e na sala de aula como lócus da matéria de pensamento que se convoca e que é de natureza plural e coletiva, ainda que a exercitemos singularmente. A didática é uma prática, neste caso assumidamente uma tentativa, tanto mais quanto mais nos aproximamos de um caráter de ensaio, tendo como base as proposições dos encontros que inspiraram este artigo. Pequenos fatos exemplificam como esta didática do acesso que hoje defendemos conceitualmente, teve origem em experiências muito práticas, ordinárias e desafiadoras através da pele-corpo-sala-de-aula. A professora-aprendiz é quem nos conta:

\section{Situ-ação 1}

Como irrompimento da barreira autoritária entre professor-aluno que notei em muitos corpos ingressantes no ensino superior, fruto de suas experiências prévias em salas de aula, observei que mencionar, de início, uma bibliografia que pertence à composição do meu corpo (docente), mas que é anterior a qualquer pretensão profissional, tinha a capacidade de autorizá-los a percorrer seus acervos prévios também e considerar os saberes alcançados até àquele momento como pontos de partida para as práticas de ensino e expressão que viriam propor. Assim, referia o clássico juvenil O Mundo de Sofia (GAARDER, 1995), parte da minha formação como préadolescente e cuja matéria nutria o pensamento que expunha. Era interessante notar o entusiasmo com que reconheciam valor em suas práticas e leituras prévias, não importando se elas não correspondiam ao que denominamos produção acadêmica. Os ávidos leitores de Harry Potter faziam o trabalho de revisitar a obra para pinçar estratégias e conceitos que lhes cabiam, por exemplo. Aliás, a saga do aprendiz de mago se dá em uma escola, não é mesmo? Outros haviam lido também o título de Jostein Gaarder e reconheciam os trechos que eu citava, complementando, rebatendo, atraídos à discussão de pensar-se como corpos atuantes no mundo. Descobrir o que sabiam fazia-os mais interessados ao encontro do que desconheciam e, especialmente importante, ao que desconheciam de si.

Por exemplo, um malabarista com extremo domínio físico para a técnica se via desnudado em relação à sua voz, inseguro, e a considerava menos interessante do que seus empenhos físicos. Quando sugerimos que experimentasse o malabarismo através de seus recursos vocais pudemos ver nascer vozes inaugurais naquele corpo, sendo investigadas, até então desconhecidas pelo próprio protagonista que as descobria e que se autorizava a ensaiar novos 
discursos, entonações, ritmos etc. No trânsito entre malabares e potências vocais um outro desdobramento se anunciou através do acoplamento destes saberes quando, em sala de aula, posteriormente, em seu estágio docente, o estudante recorreu ao adensamento das experiências ao malabar como técnica de origem-, variando-o para acessar novos modos e meios de promover conteúdos previstos e os inaugurais que se habilitava a também descobrir nos corpos de seus estudantes. Se esta é uma técnica de peso, agilidade, atenção e efeito, por que não lhe serviria para compor sua própria didática, sua invenção de procedimentos operantes em sala de aula? Habilitando outros corpos, como consequência. Tal feito não poderia ser-lhe transmitido uma vez que eu não domino a execução do malabar, mas revelou-se uma rica fonte de estudos e recursos (de forças) a serem derivados como didática daquele estudante, agora professor.

\section{Situ-ação 2}

Lidando com adolescentes, na fase da combustão de seus hormônios, conto que na minha primeira experiência em sala de aula como professora contratada em uma universidade, encontrar com seus impulsos sexuais se revelou um desafio à parte. Em quase todas as aulas de expressão corporal no primeiro semestre de 2014, bastava eu me virar de costas e me distrair um pouco procurando uma música ou organizado as folhas de chamada que, ao virar-me de volta havia muitos órgãos genitais desenhados no quadro branco. E, se não se pode vencê-los, junte-se a eles, diz o famoso enunciado. Não, eu não fui desenhar órgãos genitais com os estudantes, mas os convidava a refletir sobre tais ações, o desenho era uma "expressão corporal", matéria da aula, afinal, não é mesmo? Se eles queriam me provocar, eu os provocava de volta! E acho que neste tanto de estímulo nos fortalecemos como corpos pesquisadores-artistas, performers-pensadores, professores-aprendizes. Incorporar o conhecimento que traziam: eu propunha pliés, relevés, acessos aos pontos de equilíbrio e desequilíbrio do movimento, desenhos de formas nas figuras-corpos, e eles ensinavam a execução do "quadradinho de oito" (prática de fragmentação de movimento com o quadril e as mãos postas nos joelhos, parte coreográfica de um bit da época), ou aprendíamos a técnica de malabares com os meninos que tinham atuado no circo, ou os princípios de uma arte queer ${ }^{10}$ com os corpos que traziam e descobriam tais aspectos manifestos em suas expressões. Compartilhamento de saberes: uma didática da investigação expandida, poderíamos pensar! Apagamento da distância entre cultura popular, prática circense e técnicas de dança mais tradicionais neste exemplo; das distâncias entre produção acadêmica e produção de saberes-experiência; da distância entre ensinar e aprender; da distância entre professor e aluno; da distância entre um antropólogo e uma cultura que ele observa. A aula então como um ritual de acesso aos corpospensamento, cuja matéria que se põe a mover se manifesta aberta, descoberta, ensaiando-se, estranhando o próprio "si": aí produzindo conhecimento. Apagamento das distâncias para tentar inaugurar variações, diferenças. Exercícios de uma “[...] política cognitiva da invenção de si e do mundo" (KASTRUP, 2005).

Abrir os espaços para os saberes, acreditamos, também contribui para abrir os espaços nos corpos e nas expressões, nas criações e composições, nos processos de ensino e práticas

\footnotetext{
${ }^{10}$ Corpos queer são construções sociais e culturais. Arbitrariamente transitam entre gêneros opondo-se às dualidades, manifestam-se na pluralidade de forças moleculares de expressão, subvertendo aspectos identitários. Como exemplos de corpos queer poderíamos referir o ator brasileiro Silverio Pereira, ou um cantor como Freddy Mercury, da banda inglesa Queen, por exemplo, ou a cantora brasileira Liniker, nos quais os corpos estão libertos das representações dualistas entre gêneros, movendo entre as expressões. Queer são "seres do nosso tempo", "a social matter" (FREEMAN, 2005, p. 61) produzidos pelas forças de uma contemporaneidade que os atravessa. Sobre teoria queer, ver os estudos de Judith Butler (1993; 2010).
} 
pedagógicas, especialmente para o que se desconhece, o que caracterizaria a aprendizagem na concepção que defendemos. Ao experimentarmos saídas, relativizamos os lugares de poder e permitimos que se descubram procedimentos próprios. Certamente o sucesso desta didática expandida que expomos desdobra-se pelo tanto de fracasso que se ensaiou coletivamente também: exercícios que não produziram o que se pretendia, explicações que não alcançaram "compreensão", forças extenuadas em alguns encontros, corpo esgotado em outros. Talvez o tanto que aceitei a possibilidade das fraquezas, expondo-as como parte do percurso, afinal, tenha autorizado a aventurarem-se também em suas proposições pedagógicas, ensaios didáticos, expressões compositivas. Uma certa vulnerabilidade que tem como consequência a força de autorizar-se, acessar, desdobrar-se, descobrir. E, neste ensaio de forças menos potentes, desvios de atenções, no acolhimento de saberes, ver nascer o interesse dos estudantes em ensinar, autorizados pela apreensão de que o ensino seria então a eterna arte de aprender. E o interesse em descobrir modos de ensinar, especialmente, procedimentos próprios para seguir expandindo esta didática do acesso. Assim, abrindo, ver o interesse em aprender um pouco mais. Ensinar com samba poderia ser, com malabarismo como foi, em acordo com o que cada coletivo, em suas singularidades, oferece. Promover a performance a um ato pedagógico (CASSURIAGA, 2018), redigir uma monografia em formato de revista para torná-la acessível às dragqueens, seu objeto de estudos (SILVA, 2017), ou reconhecer-se uma "bicha preta" e defender o lugar de um saber próprio que passa por tais termos (BUENO, 2019), por exemplo. Estas foram algumas das descobertas que pude testemunhar a partir de uma didática que expunha de antemão as forças e que, tendo-as como princípio operativo, convocava às experiências de pensamento.

\section{TERCEIRO MOVIMENTO - VALIDAR AS DESCOBERTAS: OS PROFESSORES DE PROCEDIMENTOS PRÓPRIOS}

Como consequência dos dois movimentos apresentados: acessar e descobrir, o terceiro movimento requereria a validação do pensamento que se experimentou. A qualidade inaugural muitas vezes antecipa um olhar de desconfiança, dúvidas para com a recente descoberta. Porque a diferença reside no seio da criação, precisamos olhar para tais rasgos que se riscam em estruturas tradicionais, conservadoras, muitas vezes aniquiladoras do pensamento, contemplandoos com o exercício da avaliação sem julgamentos. A apreciação do movimento da diferença deve considerar as potências, as forças, a produção de pensamento e, em seguida, submetê-lo a novas relações na verificação de operações possíveis, atentando para onde segue abrindo e onde inibiria as aberturas. Como diz Kafka, "[...] não se trata de liberdade, mas de achar saídas" (DELEUZE, GUATTARI, 2014, p. 67-68). Essa didática de acesso seria um exercício constante, supomos, de procurar as saídas. E aí, nesta investigação, voltaríamos à relevância da pele: palco das percepções. Pele aqui como um conceito aberto também, que não prevê apenas o tátil, mas todo o conjunto de sentidos que faz com que um corpo se afirme no mundo e componha-se também por ele. No maior órgão do corpo humano reside uma qualidade de acesso a possíveis operações menores nas práticas didáticas e criativas dos corpos, um saber residual que requer ser treinado como emancipação para diferir. E, com a saída que uma bibliografia atípica para um artigo científico proporia, lembrar que "[...] nascer é receber de presente o mundo inteiro" (GAARDER, 1998, p. 49).

Então, porque o professor é um corpo no mundo na incumbência do ensino, fazendo de si matéria do que o pensamento põe a funcionar, é a sua percepção em contínuo estado de aprendizagem - aprimoramento - que também lhe cabe exercitar. Estando-se nas aulas não como 
na estreia, mas assumindo-as como ensaios. "Ampliar a percepção quer dizer tornar sensíveis, sonoras (ou visíveis) forças ordinariamente imperceptíveis" (DELEUZE, 2016, p. 317). Válido dizer que se trata de um exercício de vida em relação aos sentidos corporais, atividade perene, inesgotável. Assim, uma atenção voltada às nossas capacidades de sentir em dupla acepção: tanto como atravessamento de forças em um corpo (afecções) como pela ampliação das habilidades sensoriais de estar no mundo (percepções). Resgatar nos corpos a potência de acontecer seria ambição deste corpo ensinoaprendiragem, como explica Luiz Fuganti (2007, p. 69):

Na medida mesma em que nós perdemos a capacidade de acontecer, nós não sabemos mais qual a fonte ou o motor do nosso desejo. Não sabemos mais qual é a fonte ou o motor do movimento do corpo. Perdemos o sentido das velocidades e lentidões, dos seus fluxos que redistribuem o desejo. Não apreendemos mais, senão confusa e indiretamente, as modificações que afetam um corpo intensivo e o fazem mudar seu destino.

A abertura dos sentidos, entradas para a percepção, alarga-se sobretudo quanto mais atentamos, perscrutamos, esburacamos e vasculhamos suas possibilidades, quando se revelam como acessos a corpos mais potentes. Nutrindo as capacidades de um corpo de produzir acontecimentos, a pele -por sua qualidade de superfície de contato com o mundo- surge como estímulo às propulsões de novos modos de estar em relação com o mundo e, assim, de produzir novos mundos.

Nossos sentidos - visão, audição, olfato, tato, gosto - são todos órgãos de fazer amor com o mundo, de ter prazer nele. Mas não basta ter olhos, nariz, ouvidos, língua, pele. [...] Roland Barthes sugeriu então que a educação dos sentidos fosse semelhante ao Kama Sutra, o ensino das várias posições possíveis de se fazer amor com o mundo. Mas isso, é claro, exige que os professores sejam mestres na dita arte. (ALVES, 2018, p. 24)

Nos ensaios, trabalhamos frequentemente com estados de corpo enquanto nas práticas pedagógicas nos vemos invariavelmente diante dos estados de conhecimento, dos exercícios de aprendizagem. Entretanto, ambos têm em comum a pretensão de produção do pensamento, acreditamos. Os estados de corpo em suas expressividades, formas e contornos, rasgos e preenchimentos, procedimentos didáticos e práticas abertas às descobertas, são então traços de forças sensíveis em consonância com os estados de coisas do mundo. "Pelos sentidos educados, deixamos de 'usar' o mundo e passamos a 'fazer amor' com o mundo" (ALVES, 2018, p. 48). Com o trabalho sobre os sentidos alcançamos os estados que se expressam nas formas, nas qualidades de movimento, nos gestos, na estrutura inteira do corpo que, por sua vez, retroalimenta os estados. "Estados de corpo" são estados transitórios que um corpo experimenta, mobilizado pelas forças dos afetos. Os estados de corpo reverberarão nas qualidades gestuais, vocais e de movimento que os corpos arrastam em seus processos de criação e aprendizagens. Assim, os estados poderão ser mais ou menos propensos à promoção de variações, e por isso o trabalho sobre eles ampliaria as capacidades de derivar (variação), de alcançar devires ou de afetar dos corpos. Nas salas de aula, o professor que está à frente, como condutor, deve experimentarse também atrás, por baixo, em cima, ao lado, o movimento permite rever os saberes, engendrar novos modos de acesso aos seus estudantes, vê-los ampliarem-se no exercício sobre os sentidos, os papeis, os ofícios, através do estudo das percepções e atenções. Aqui, apresentamos a "eficácia" em considerar de antemão o trabalho das forças sobre nossas matérias corpopensamento. "Somos nosso corpo. [...] Toda educação passa pelo corpo. Toda educação é educação dos sentidos." (STRAZZACAPPA, 2012, p. 75) 
Assim, pelo trabalho sobre as percepções, o aguçamento dos sentidos, a desierarquização de saberes, pelo exercício de procurar saídas que acaba por abrir os corpos, e pelas aberturas que são acessos a novos modos e procedimentos, ver nascer professores que diferem, minoram, inventam didáticas. Exemplo disso são os procedimentos que os próprios estudantes encontraram em seus novos modos de fazer: pela pedagogia da performance, por um TCC que é uma revista LGBTQIA+, por um teatro das bichas pretas, enfim pelas necessárias invenções que promoveram como derivação do que se cria. Aliás, "[...] a figura do professor se confunde com o próprio artista” (STRAZZACAPPA, 2012, p. 45). A consequência inevitável de uma didática do acesso seria a criação de espaços, de saberes, relativização de poderes e contínua variação de didáticas inventadas. Como nos ensaios, a experimentação se firmaria como premissa do que se entende por aprender. Não mais transmitir de um corpo a outro, mas transmutar nos próprios corpos: começando pelo do professor, impreterivelmente.

\section{DIDÁTICA DO ACESSO AOS CORPOS}

Os apontamentos possíveis a partir dos movimentos apresentados direcionam para uma didática que se marca como exercício, continuamente ensaiada, enfraquecendo-se, revelando suas vulnerabilidades, abrindo, fortalecendo-se de novo, descobrindo, abismando-se e estranhando pelo entranhamento, autorizando, erguendo procedimentos e permitindo a emancipação dos corpos em suas práticas pedagógicas. Como vimos, o trabalho sobre as forças, os sentidos e as percepções, requer que o professor se exponha como experimento de tais condições também. Ora, é a sua pele o exemplo de ensino, não é mesmo? "É no encontro no plano das forças [...] que pode ser flagrado o devir-mestre" (KASTRUP, 2005). Aliás, sala de aula como reunião coletiva cuja diferença deve ser promovida e não apagada. Se reduzimos as distâncias entre ofícios e práticas, ensino e ensaio, acoplando professores-artistas, meio pedagogos-poetas, mestres-aprendizes, um pouco enfraquecidos às vezes, é para fazer passar forças de aprendizagem inaugurais. Criando e inventando tentativas de "[...] viver poeticamente o ofício docente" (AQUINO, CORAZZA, ADÓ, 2018). Pensando outramente, à luz de uma antropologia, "[...] pensar outra mente, pensar com outras mentes" (VIVEIROS DE CASTRO, 2015, p. 25) como forma de aproximação cuja consequência seria cavar acessos, aberturas, "[...] mudando a pessoa e a coisa que somos". Pôr o nosso corpopensamento-professor em estado de ensaio. Aliás, ensaios para uma estreia que se faria sempre adiante, no corpo do outro, autorizando os estudantes em seus procedimentos pedagógicos próprios, descobertos através de suas peles e percepções, de seus sentidos, investindo no que inventam por uma didática do acesso. O corpo de um professor que se arrisca, seja propondo estratégias de ensino ou ensaiando procedimentos de acesso aos movimentos do pensamento, acaba ensinando por demonstração também. $O$ exemplo do mestre que se põe em risco quando cria, reverbera autorizando os corpos a também se arriscarem às criações de novos corpos e estratégias, pensamentos e práticas: observa-se que a ação do professor-aprendiz age por contágio.

Os papeis e as experiências se adensam, e os apontamentos exibidos permitem-nos afirmar que ensinar é ensaiar-se continuamente como papel social, função pedagógica, deformação no ventre dos processos formativos, expansão pelo recolhimento do apanhado de mundo que se tem em si. Retomando a proposição da obra visual que diz "[...] atenção: percepção requer envolvimento", ensinar pelo que nos envolve - a própria pele -, parece ser um acesso para os encontros frutíferos, o alargamento dos saberes, das técnicas, para a ampliação de potências. 
Nas práticas de ensaio para o aprimoramento de performances cênicas, da lapidação de forças expressivas, trabalhamos muitas vezes com a descolonização do próprio corpo, de seus movimentos e gestos. Nas salas de aula, no enfrentamento entre normas curriculares, anseios pedagógicos, recursos didáticos, como operamos uma descolonização das práticas de ensinoaprendizagem que nos autorize a traçar novas linhas do encontro entre saberes? Nossa personagem conceitual, a professora-aprendiz, já antecipou que isto que este estudo se propõe a alegar, este ensinamento que está vinculado a uma pedagogia para a qual as reflexões convergem, é também e, antes de tudo, aprendizagem no mesmo corpo. Quer dizer que não existe uma transmissão unilateral, mas um atravessamento, uma promoção de forças que desenharia didáticas baseadas na singularidade de cada coletivo. Portanto, não transmissão, mas trânsito. Isto que estamos nos propondo a defender e expandir nos corpos alheios, este ensinamento, também somos aprendizes no nosso próprio corpo. Descobrimos um pouco que convocar a atenção para as forças promove a emancipação dos corpospensamentos.

Pensar as forças como meio de tornar acessível uma apreensão e produção de conhecimento pelas vias específicas de cada corpo. Assim, o que fortalece ou enfraquece nossa assimilação, expansão, experiência? Como cada corpo faz amor com o mundo, via técnica, ciência, conhecimento que se ensina? Assinalamos uma amplitude necessária por consequência da experiência de lecionarmos em contextos específicos, que nos levou a ansiar por aberturas, modos de acesso ao buscar saídas. Pensar a aula como co-criação.

É preciso ser professora para escrever sobre ensino? É preciso ser performer ou autor ou diretor, músico ou dramaturgo, para escrever sobre ensaio? Ou atleta para escrever sobre treinamento? Este artigo é um apanhado das experiências de indagação possíveis por um corpo que se viu na incumbência de lecionar! E de lecionar para futuros professores, especialmente.

Para seguir no exercício de fazer perguntas, a professora-aprendiz poderia pensar: e qual a minha linha? Diria que as traçamos por necessidade, e cada linha se compunha como reação de inevitabilidade-necessidade da reunião coletiva. Estar aprendiz é um lugar no mundo e na própria vida, o professor que assim se defronta com o ofício abre um orifício de impregnação do saber, da compreensão de corpos relacionais, do sentido sublime do aprimoramento técnico-científico para o desempenho de qualquer coisa, através das percepções e dos sentidos, como nos diz Rubem Alves. Ensaiar para procurar aquilo que nem sabíamos que, na verdade, tínhamos a dizer ou fazer no mundo. Produzindo pensamento. Talvez, o que estejamos aqui referindo e defendendo diga respeito, antes de mais nada, a uma qualidade coletiva que é sempre uma tomada de decisão. Nos ensaios, em uma produção cênica, encontramos esta necessidade em cada acordo que se estabelece na reunião de artistas. Nas artes cênicas contemporânea, de forma crescente, o diretor autoritário e autocrático tem cedido lugar ao operador de criações coletivas, deixando de vez o lugar do idealizador que necessita de intérpretes em privilégio de um criador que requer criadores. Da mesma forma, parece-nos, a sala de aula tem sido cada vez mais um espaço onde a transmissão de conhecimento tem dado lugar às produções de pensamento. "Não poderemos existir, no plano ético-intelectivo, sem a trilha aberta pelos sinais vocais emitidos por um professor, aos quais retribuímos na medida dos nossos pulmões - algumas vezes, com um murmúrio; outras, comum estrondo" (AQUINO, CORAZZA, ADÓ, 2018). Este lugar corpopele de professor que é um mestre e se aproxima de um maestro, compondo e criando, quase sem distância entre o artista e o docente, entre o poeta e o pedagogo. Aliás, aprendemos com Mario Quintana (2007, p. 78):

$$
\text { Pequeno poema didático }
$$


O tempo é indivisível. Dize, Qual o sentido do calendário. Tombam as folhas e fica a árvore Contra o vento incerto e vário.

A vida é indivisível. Mesmo

A que se julga mais dispersa

E pertence a um eterno diálogo

A mais inconsequente conversa

Todos os poemas são um poema, Todos os porres são o mesmo porre, Não é de uma vez que se morre...

Todas as horas são horas extremas!

O que o professor tem em mãos não é exatamente o conhecimento que transmite, mas as forças de promoção do novo, uma experiência que pede a urgência das horas, como nos lembra Quintana. O professor que assim se cria, autoriza criações que decorrerão na invenção de modos e procedimentos, em didáticas próprias, corpos de potência em suas relações com o mundo. Movimentos ensaiados no ensino: acessos às saídas das rigidezes edificantes. Por fim, fazer amor com o mundo é permitir que se concebam novos mundos.

\section{REFERÊNCIAS}

ADÓ, Máximo Daniel Lamela. Educação da diferença: possibilidades de composição. X Anped Sul, Florianópolis, 2014.

ALVES, Rubem. A educação dos sentidos: conversas sobre a aprendizagem e a vida. São Paulo: Planeta do Brasil, 2018.

AQUINO, Julio Groppa; CORAZZA, Sandra Mara; ADÓ, Máximo Daniel Lamela. Por alguma poética na docência: a didática como criação. Educ. rev. Belo Horizonte, v. 34, 2018.

ATTIWILL, Suzie. et al. Practicising with Deleure: design, dance, art, writing, philosophy. Edimburgo: Edinburgh University Press Ltd., 2017.

BARBA, Eugênio; SAVARESE, Nicola. A arte secreta do ator: dicionário de antropologia teatral. São Paulo: Hucitec/Ed. Unicamp, 1995.

BALESTRERI, Silvia. Boal e Bene: contaminações para um teatro menor. Tese de Doutorado. Psicologia clínica. São Paulo: PUCSP, 2004.

BALESTRERI, Silvia. Carmelo Bene: notícias de um teatro menor. Revista Cena. UFRGS, Porto Alegre, v. 4, p. 91-99, 2005.

BUENO, Rafael de Camargo. Segura aí: a construção de um experimento cênico das bichas pretas. 50f. Curso de Teatro - Licenciatura, Centro de Artes, Universidade Federal de Pelotas, 2019.

BUTLER, Judith. Bodies that matter: nos limites discursivos do sexo. New York: Taylor \& Francis Books, 1993.

BUTLER, Judith. Problemas de gênero: feminismo e subversão da identidade. Rio de Janeiro: Civilização Brasileira, 2010. 
CASSURIAGA, Athila. $A$ arte da performance na educação: um relato e uma proposta no ensino. $68 \mathrm{f}$. Curso de Teatro - Licenciatura, Centro de Artes, Universidade Federal de Pelotas, 2018.

CASTELUCCI, Romeo. Sobre o conceito de rosto no filho de Deus. cartografias.mitsp_01, Revista de Artes Cênicas, São Paulo: ECA, 2014.

DELEUZE, Gilles. Sobre o teatro. Rio de Janeiro: Jorge Zahar, 2010.

DELEUZE, Gilles. Francis Bacon: lógica da sensação. Rio de Janeiro: Jorge Zahar, 2007.

DELEUZE, Gilles. Dois regimes de loucos: textos e entrevistas (1975-1995). São Paulo: Ed. 34, 2006.

DELEUZE, Gilles; GUATTARI, Félix. Kafka: por uma literatura menor. Belo Horizonte: Autêntica, 2014.

DELEUZE, Gilles; GUATTARI, Félix. O que é filosofia? São Paulo: Editora 34, 1992.

DELEUZE, Gilles; GUATTARI, Félix. Mil Platôs: capitalismo e esquizofrenia 2, v. 3. São Paulo: Editora 34, 2012.

FREEMAN, Elizabeth. Time binds or erotohistoriography. Durham: Duke University Press, 2005.

FOUCAULT, Michel. Ditos e escritos: estética - literatura e pintura, música e cinema. Rio de Janeiro: Forense Universitária, 2001.

FOUCAULT, Michel. Vigiar e punir: nascimento da prisão. Petrópolis: Vozes, 2004.

FUGANTI, Luiz. Corpo em devir. Revista Sala Preta, v. 7, 2007. p. 67-76.

GAARDER, Jostein. O Mundo de Sofia: romance da história da filosofia. São Paulo: Companhia das Letras, 1995.

GAARDER, Jostein. Através do espelho. São Paulo: Companhia das Letras, 1998.

GIANOUKAS, Lindsay. Performance da própria pele: forma, forças, fuga e o fora. Anais ABRACE, v. 19, n. 1, 2018. Disponível em https://hosting.iar.unicamp.br/. Acesso em 15 nov. 2020.

GIANUCA, Lindsay. Pele de performer: pensamento poroso e carne expressiva. Tese de Doutorado. Programa de Pós-Graduação em Artes Cênicas, Universidade Federal do Rio Grande do Sul, 2020.

GIANUCA, Lindsay T. Corpos da cena contemporânea: virtuose, violência e autoria. Anais do IX Congresso da ABRACE, v. 17, n. 1, 2016a. p. 270-289. Disponível em https://www.publionline.iar.unicamp.br/. Acesso em 17 nov. 2020.

GIANUCA, Lindsay. Corpos da cena contemporânea: pedagogia da violência. Anais do $V$ SIGAM UFPEL, 2016b. p. 55-69.

HOUAISS, Antônio; VILLAR, Mauro de Salles. Dicionário Houaiss de língua portuguesa. Rio de Janeiro: Objetiva, 2009.

KASTRUP, Virgínia. Políticas cognitivas na formação do professor e o problema do devirmestre. Educação e Sociedade, Campinas, v. 26, n. 93, p. 1273-1288, dez. 2005.

MUNTADAS, Antoni. Atenção. 2002. Serigrafia: 66 x $102 \mathrm{~cm}$. Disponível em https://www.galerialuisastrina.com.br/artistas/muntadas/. Acesso em 17 ago. 2020.

QUITANA, Mario. Nova antologia poética. São Paulo: Globo, 2007.

RANCIÈRE, Jacques. O mestre ignorante: cinco lições para a emancipação intelectual. Belo Horizonte: Autêntica, 2004. 
SILVA, Gengiscan Pereira. Abigail: discursos sobre o fazer drag. 72f. Curso de Teatro Licenciatura, Centro de Artes, Universidade Federal de Pelotas, 2017.

SONTAG, Susan. A vontade radical. São Paulo: Companhia das Letras, 1987.

STRAZZACAPPA, Márcia. Dançando na chuva... e no chão de cimento. In: FERREIRA, Sueli (org.). O ensino das artes: construindo caminhos. Campinas, São Paulo: Papirus, 2012. p. 39-78.

VIVEIROS DE CASTRO, Eduardo. Metafisicas canibais: movimentos para uma antropologia pósestrutural. São Paulo: Cosac Naify, 2015.

ZORDAN, Paola. Gaia educação: arte e filosofia da diferença. Curitiba: Appris, 2019.

Submetido em agosto de 2020

Aprovado em novembro de 2020

\section{Informações das autoras}

Lindsay Gianuca

Doutoranda do Programa de Pós-Graduação em Artes Cênicas da Universidade Federal do Rio Grande do Sul

E-mail: lindsaygianuca@gmail.com

ORCID: https://orcid.org/0000-0002-0817-6508

Link Lattes: http://lattes.cnpq.br/3986758138608989

Silvia Balestreri

Professor do Departamento de Arte Dramática e no Programa de Pós-Graduação em Artes Cênicas do Instituto de Artes da Universidade Federal do Rio Grande do Sul

E-mail: silvia.balestreri@ufrgs.br

ORCID: https://orcid.org/0000-0002-9538-542X

Link Lattes: http://lattes.cnpq.br/7439171356537261 